\title{
PENGARUH METODE SOSIODRAMA \\ TERHADAP KEMAMPUAN MENENTUKAN UNSUR INTRINSIK CERPEN SISWA KELAS V SD NEGERI 131 PEKANBARU
}

\author{
Ella Miranda \\ ellamiranda314@gmail.com \\ Pendidikan Guru Sekolah Dasar FKIP Universitas Riau
}

\begin{abstract}
The background of this study is the lack of student attention to learning material. This study aims to describe the influence and differences in the ability to determine the intrinsic elements of students' short stories using the sociodrama method. This research was conducted in class V SD Negeri 131 Pekanbaru. Based on the results of the study it was found that there is an influence of the ability to determine the intrinsic element in the experimental class as seen from the average of the initial test and the final test, namely the initial test of 60.63 to 81.88 when the final test with a large influence of $56 \%$. In the final test of the control class and the experimental class obtained $t$ count $=21,708 \geq t$ table $=1,999$, so there is a difference in the ability to determine the intrinsic element between the control class and the experimental class. So, there is an influence (experimental class) and differences in abilities (between the control class and the experimental class) fifth grade students of SD Negeri 131 Pekanbaru.
\end{abstract}

Keywords: sociodrama method, ability to determine intrinsic elements

\section{ABSTRAK}

Latar belakang penelitian ini adalah kurangnya perhatian siswa terhadap materi pembelajaran. Penelitian ini bertujuan untuk mendeskripsikan pengaruh dan perbedaan kemampuan menentukan unsur intrinsik cerpen siswa menggunakan metode sosiodrama. Penelitian ini dilakukan di kelas V SD Negeri 131 Pekanbaru. Berdasarkan hasil penelitian ditemukan bahwa ada pengaruh kemampuan menetukan unsur intrinsik pada kelas eksperimen terlihat dari rata rata tes awal dan tes akhir yaitu tes awal sebesar 60,63 menjadi 81,88 saat tes akhir dengan besar pengaruh 56\%. Pada tes akhir kelas kontrol dan kelas eksperimen diperoleh $t_{\text {hitung }}=21,708 \geq t_{\text {tabel }}=1,999$, sehingga ada perbedaan kemampuan menentukan unsur intrinsik antara kelas kontrol dan kelas eksperimen. Jadi, terdapat pengaruh (kelas eksperimen) dan perbedaan kemampuan (antara kelas kontrol dan kelas eksperimen) siswa kelas V SD Negeri 131 Pekanbaru.

Kata Kunci: metode sosiodrama, kemampuan menentukan unsur intrinsik

\begin{tabular}{|c|c|c|}
\hline Submitted & Accepted & Published \\
\hline 04 September 2019 & 16 September 2019 & 24 September 2019 \\
\hline
\end{tabular}

\begin{tabular}{|l|c|c|c|}
\hline Citation & $:$ & $\begin{array}{r}\text { Miranda, E. (2019). Pengaruh Metode Sosiodrama terhadap Kemampuan Menentukan Unsur Intrinsik Cerpen Siswa Kelas } \\
\text { V SD Negeri 131 Pekanbaru. Jurnal PAJAR (Pendidikan dan Pengajaran), 3(5), 1173-1179. DOI: } \\
\text { http://dx.doi.org/10.33578/pjr.v3i5.7897. }\end{array}$ \\
\hline
\end{tabular}

*Copyright $@ 2019$ Jurnal PAJAR (Pendidikan dan Pengajaran) Publish by PGSD FKIP Universitas Riau, Pekanbaru, Indonesia

\section{PENDAHULUAN}

Mata pelajaran bahasa Indonesia adalah salah satu mata pelajaran yang sangat penting di sekolah. Mata pelajaran bahasa Indonesia sudah diajarkan mulai dari jenjang pendidikan Sekolah Dasar. Bahasa Indonesia merupakan salah satu identitas bangsa Indonesia. Akan tetapi pada kenyataannya selama proses pembelajaran siswa kurang berinteraksi dan sulit memahami materi bahasa Indonesia. Di dalam pelajaran bahasa sangat banyak materinya yaitu mengenai cerpen, karangan, paragraf, pantun puisi. Salah satunya adalah menentukan unsur intrinsik cerpen.

Agar siswa berkemampuan dalam menentukan unsur intrinsik cerpen, tentunya harus ada pendukung yang bisa memacu dan mendorong kemampuan siswa, sehingga kemampuan siswa menjadi lebih baik. . Guru adalah sebagai salah satu sumber belajar yang berkewajiban menyediakan lingkungan belajar yang kreatif bagi kegiatan belajar peserta didik di kelas yaitu 
menggunakan metode pembelajaran yang tepat agar suasana kelas dapat menjadi bersemangat dan menyenangkan.

Ada beberapa faktor yang menyebabkan kemampuan menentukan unsur intrinsik cerpen siswa rendah yaitu : proses belajar kurang menarik, cara mengajar guru yang kurang bervariasi yaitu dengan hanya membacakan saja (metode ceramah), Hal ini membuat siswa mengantuk sehingga jadi malas belajar. Apabila belajar dengan hanya membacakan saja atau metode ceramah ini terus- menerus dilakukan maka yang akan terjadi adalah siswa akan merasa bosan dan tidak tertarik dengan proses belajar mengajar.

Permasalahan di atas terdapat solusi untuk mengatasinya, yaitu dengan menggunakan metode sosiodrama. Pembelajaran menggunakan metode sosiodrama dapat memberikan pengaruh terhadap hasil belajar siswa sebagaimana yang dikemukakan oleh Shomer (dalam Premita Sari Octaviana,2017:35) bahwa permainan drama membantu peserta didik mempertahankan materi pembelajaran di sekolah dalam hal memori mereka. Dalam kegiatan pembelajaran siswa tidak hanya memahami teori saja, tetapi mempraktekkan secara langsung.

Menurut Tristiantari (2017) metode pengajaran sosiodrama mengarahkan siswa untuk berada dalam situasi peran di mana mereka harus mendapatkan pendapat, berdebat, dan menemukan solusi jika ada perbedaan pendapat.Keberhasilan siswa dalam menjalankan peran itu akan menentukan apakah proses pemahaman, penghargaan, dan identifikasi nilai perkembangan (Hasan, 2009).

Pembelajaran pada materi cerpen ini mengarahkan siswa untuk bisa menentukan unsur-

\section{KAJIAN TEORETIS}

Menurut Sanjaya dalam Istarani (2012) metode adalah cara yang dapat digunakan untuk melaksanakan strategi. Metode secara harafiah berarti cara. Dalam pemakaian yang umum, metode diartikan sebagai suatu cara atau prosedur yang dipakai untuk mencapai tujuan tertentu.

Metode sosiodrama adalah suatu metode yang pembelajarannya dengan bermain peran unsur intrinsik (tema, tokoh, watak/sifat, latar, amanat) yang terdapat pada cerpen melalui pembelajaran dengan metode sosiodrama.

Berdasarkan penjelasan di atas, maka peneliti akan melakukan penelitian dengan judul "Pengaruh Metode Sosiodrama Terhadap Kemampuan Menentukan Unsur Intrinsik Cerpen Siswa Kelas V SD Negeri 131 Pekanbaru".

Rumusan masalah pada penelitian ini adalah "Apakah terdapat pengaruh metode sosiodrama terhadap kemampuan menentukan unsur intrinsik cerpen pada kelas eksperimen?" dan apakah terdapat perbedaan kemampuan menentukan unsur intrinsik cerpen antara kels eksperimen dengan kelas kontrol?". Pada penelitian ini memiliki tujuan untuk mendeskripsikan pengaruh metode sosiodrama terhadap kemampuan menentukan unsur intrinsik cerpen pada kelas eksperimen dan mendeskripsikan perbedaan kemampuan menentukan unsur intrinsik antara kelas eksperimen dan kelas kontrol Penelitian ini juga dapat memberikan manfaat kepada beberapa pihak yaitu: (1) bagi siswa, Dengan metode sosiodrama siswa dapat lebih termotivasi dan lebih tertarik untuk belajar sehingga proses pembelajaran menyenangkan dan dengan mudah memahami lalu menentukan unsur intrinsik cerpen; (2) bagi guru, Dengan memilih metode sosiodrama, muncul kesadaran guru untuk lebih memilih sarana media yang tepat bagi siswanya; (3) bagi sekolah, Penelitian ini dapat memberikan pencerahan agar mengadakan perbaikan dalam proses belajar mengajar; (4) bagi peneliti, Peneliti sebagai mahasiswa calon guru diharapkan dapat menambah pengetahuan atau wawasan tentang pentingnya manfaat metode pembelajaran yang menarik bagi siswa.

untuk memecahkan masalah yang berkaitan dengan fenomena sosial, fenomena yang menyangkut hubungan antar manusia.

Menurut Moreno dalam Siyat Ulon (2018)" Sociodrama is a methodology that emerged from the theory and practice of its founder, Jacob L. Moreno, a Romanian-American psychiatrist and sociologist". Sociodrama adalah 
metodologi yang muncul dari teori dan praktik pendirinya, Jacob L. Moreno, seorang psikiater dan sosiolog Rumania-Amerika.

Menurut Vygotsky dalam Alain Bengochea (2018) "characterized sociodramatic play as an event that helped to propel their development forward as they create imaginary situations, adopt and act out roles, and follow rules determined by those roles. Through immersing themselves in an imaginary situation, children develop and act upon internalized representations of their environment, performing independently of the constraints imposed by the physical landscape around them". menandai permainan sosiodramatik sebagai peristiwa yang membantu mendorong perkembangan mereka saat mereka menciptakan situasi imajiner, mengadopsi dan memerankan peran, dan mengikuti aturan yang ditentukan oleh peran tersebut. Dengan membenamkan diri dalam situasi imajiner, anakanak berkembang dan bertindak berdasarkan representasi lingkungan mereka yang terinternalisasi, yang bekerja secara independen dari kendala yang ditimbulkan oleh lanskap fisik di sekitar mereka.

Adapun kelebihan dan kelemahan dari metode sosiodrama menurut Djamarah (2010) adalah sebagai berikut: 1) peserta didik akan terlatih untuk berinisiatif dan berkreatif. Pada waktu bermain drama pemain dituntut untuk mengemukakan pendapatnya sesuai dengan waktu yang tersedia; 2) peserta didik melatih dirinya untuk melatih, memahami dan mengingat, menghayati isi bahan yang akan didramakan; 3) bakat yang terdapat pada peserta didik harus dipupuk sehingga dimungkinkan akan muncul atau

\section{METODE PENELITIAN}

Peneliti melaksanakan penelitian di kelas II Sekolah Dasar Negeri 131 Pekanbaru yang beralamat di JL. Perkasa No.1, Rejosari, Tenayan Raya. Penelitian dilaksanakan pada bulan April sampai Mei 2019. Jenis penelitian merupakan penelitian kuantitatif yang bertujuan untuk mendeskripsikan pengaruh metode sosiodrama terhadap kemampuan menentukan unsur intrinsik kelas eksperimen dan perbedaan kemampuan antara kelas kontrol dan kelas eksperimen. tumbuh bibit seni drama dari sekolah; 4) kerjasama antar pemain dapat ditumbuhkan dan dibina dengan sebaik-baiknya; 5) bahasa lisan peserta didik dapat dibina menjadi bahasa yang baik dan benar agar mudah dipahami oleh orang lain; 6) siswa memperoleh kebiasaan untuk menerima dan membagi tanggung jawab dengan sesamanya.

Kelemahan metode sosiodrama adalah sebagai berikut: 1) banyak memakan waktu, baik waktu persiapan dalam rangka pemahaman isi bahan pelajaran maupun pada pelaksanaan pertunjukan; 2) sebagian besar peserta didik yang tidak ikut bermain drama mereka menjadi kurang kreatif; 3) sering kelas lain terganggu oleh suara pemain dan para penonton yang kadang-kadang bertepuk tangan dan lain sebagainya; 4) memerlukan tempat yang cukup luas, jika tempat bermain sempit menjadi kurang bebas.

Cerita pendek atau biasa disebut cerpen adalah suatu bentuk prosa naratif fiktif atau cerita rekaan yang pendek yang cenderung padat yang langsung pada tujuannya (Yulisna, 2017). Kemampuan menentukan unsur intrinsik cerpen yaitu kemampuan untuk menyelidiki unsur intrinsik (tema, tokoh, watak/sifat, latar dan amanat).

Berikut pengertian masing-masing unsur menurut Kurniaman dan Hamizi (2009) tema adalah ide sentral yang mendasari suatu cerita. Tokoh adalah Pelaku yang mengemban peristiwa dalam cerita fiksi sehingga peristiwa itu mampu menjalin suatu cerita. Watak adalah karakter tokoh yang terdapat dalam sebuah cerita. Latar adalah situasi tempat ruang dan waktu terjadinya cerita. Amanat adalah pesan moral yang disampaikan pengarang kepada pembacanya

Metode penelitian yang digunakan adalah eksperimen semu (quasi experimental), dengan desain nonequivalent control groups design. Nonequivalent control groups design, terdiri dari kelompok eksperimen dan kelompok kontrol yang tidak dipilih secara random tetapi menerima keadaan kelas apa adanya (Sugiyono, 2016).

Subjek penelitian ini adalah siswa kelas V A SD Negeri 131 Pekanbaru tahun ajaran 2018/2019 yang berjumlah 32 siswa dan siswa 
kelas V B SD Negeri 131 Pekanbaru tahun ajaran 2018/2019 yang berjumlah 32 siswa.

Teknik pengumpulan data yang dilakukan adalah teknik obeservasi dan teknik tes. Teknik observasi dengan melakukan pengamatan pengajaran bahasa Indonesia, kurikulum, RPP, metode dan silabus yang digunakan di SD Negeri

\section{HASIL DAN PEMBAHASAN}

Adapun perolehan hasil penelitian mengenai kemampuan menentukan unsur intrinsik cerpen siswa kelas V SD Negeri 131 Pekanbaru
131 Pekanbaru. Sedangkan teknik tes, dilakukan untuk mengambil data kemampuan menentukan unsur intrinsik cerpen. Menurut Arikunto (2013) "tes merupakan alat bantu atau prosedur yang digunakan untuk mengetahui atau mengukur sesuatu dalam suasana, dengan cara dan aturanaturan yang sudah ditentukan".

pada kelas eksperimen dan kelas kontrol adalah sebagai berikut:

Tabel 1 Data Kemampuan Tes Awal dan Tes Akhir Kelas Kontrol dan Kelas Eksperimen

\begin{tabular}{cccccccc}
$\begin{array}{c}\text { Sumber } \\
\text { Data }\end{array}$ & Kelas & $\begin{array}{c}\text { Jumlah } \\
\text { Siswa } \\
(\mathbf{n})\end{array}$ & $\begin{array}{c}\text { Rata- } \\
\text { Rata } \\
(\bar{x})\end{array}$ & $\begin{array}{c}\text { Standar } \\
\text { Deviasi } \\
(\mathbf{s})\end{array}$ & $\begin{array}{c}\text { Varians } \\
\left(s^{2}\right)\end{array}$ & $\begin{array}{c}\text { Nilai } \\
\text { Min }\end{array}$ & $\begin{array}{c}\text { Nilai } \\
\text { Max }\end{array}$ \\
\hline Tes Awal & Kontrol & 32 & 61,71 & 11,04 & 118,14 & 45 & 85 \\
& Eksperimen & 32 & 60,63 & 9,82 & 93,96 & 45 & 85 \\
Tes Akhir & Kontrol & 32 & 71,09 & 7,59 & 57,64 & 60 & 85 \\
& Eksperimen & 32 & 81,88 & 8,30 & 68,95 & 70 & 100 \\
\hline
\end{tabular}

Tabel 2. Hasil Uji Normalitas Kelas Kontrol dan Kelas Eksperimen

\begin{tabular}{cccccc}
\hline Sumber Data & Kelas & N & L hitung & L tabel & Keputusan \\
\hline \multirow{2}{*}{ Tes Awal } & Kontrol & 32 & 0,124 & & Normal \\
& Eksperimen & 32 & 0,143 & 0,156 & Normal \\
\multirow{2}{*}{ Tes Akhir } & Kontrol & 32 & 0,133 & & Normal \\
& Eksperimen & 32 & 0,152 & & Normal \\
\hline
\end{tabular}

Tabel 3. Hasil Uji Homogenitas Kelas Kontrol dan Kelas Eksperimen

\begin{tabular}{llllll}
\hline Sumber Data & Kelas & Varians & F hitung & F tabel & Keputusan \\
\hline \multirow{2}{*}{ Tes Awal } & Kontrol & 118,14 & 1,257 & 1,822 & Homogen \\
& Eksperimen & 93,96 & & & \\
\multirow{2}{*}{ Tes Akhir } & Kontrol & 57,64 & 1,196 & 1,822 & Homogen \\
& Eksperimen & 68,95 & & & \\
\hline
\end{tabular}

Uji Hipotesis

Tabel 4 Hasil Uji Hipotesis Kelas Kontrol dan Kelas Eksperimen 


\begin{tabular}{|c|c|c|c|c|c|c|c|}
\hline $\begin{array}{l}\text { Sumber } \\
\text { Data }\end{array}$ & Kelas & $\begin{array}{l}\text { Rata- } \\
\text { rata }\end{array}$ & $\begin{array}{c}\text { Standar } \\
\text { Deviasi } \\
\text { (s) }\end{array}$ & $\begin{array}{c}\mathrm{S} \\
\text { gabungan }\end{array}$ & t hitung & $\mathrm{t}$ tabel & Keputusan \\
\hline \multirow[t]{2}{*}{ Tes Awal } & Kontrol & 61,72 & 11,04 & \multirow[t]{2}{*}{10,45} & \multirow[t]{2}{*}{1,669} & \multirow[t]{2}{*}{1,999} & $\begin{array}{c}\text { Tidak } \\
\text { Terdapat }\end{array}$ \\
\hline & Eksperimen & 60,63 & 9,82 & & & & Perbedaan \\
\hline \multirow{2}{*}{ Tes Akhir } & Kontrol & 71,09 & 7,59 & \multirow{2}{*}{7,95} & \multirow{2}{*}{21,708} & \multirow{2}{*}{1,999} & Terdapat \\
\hline & Eksperimen & 81,88 & 8,30 & & & & Perbedaan \\
\hline
\end{tabular}

\section{Besar Pengaruh Metode Sosiodrama}

Tabel 5 Hasil Besar Pengaruh Kelas Eksperimen

\begin{tabular}{|c|c|c|c|c|c|}
\hline $\begin{array}{c}\text { Tes Kelas } \\
\text { Eksperimen }\end{array}$ & $\mathrm{N}$ & $\bar{x}$ & $\mathrm{R}$ & $\mathrm{KD}$ & $\begin{array}{l}\text { Tingkat } \\
\text { Pengaruh }\end{array}$ \\
\hline $\begin{array}{l}\text { Pretest } \\
\text { Posttest }\end{array}$ & $\begin{array}{l}32 \\
32\end{array}$ & $\begin{array}{l}60,63 \\
81,88\end{array}$ & 0,75 & 0,56 & $\begin{array}{l}\text { Berpengaruh } \\
\text { Sedang }\end{array}$ \\
\hline
\end{tabular}

\section{Kategori Kemampuan Kelas Kontrol dan Kelas Eksperimen}

Tabel 6. Data Kategori Kemampuan Kelas Kontrol dan Kelas Eksperimen

\begin{tabular}{cccccc}
\hline & & \multicolumn{2}{c}{ Kelas Kontrol } & \multicolumn{2}{c}{ Kelas Eksperimen } \\
Interval & Kategori & Tes Awal & Tes Akhir & Tes Awal & Tes Akhir \\
\hline $86-100$ & Sangat Mampu & - & - & - & 8 Siswa \\
$76-85$ & Mampu & 3 Siswa & 6 Siswa & 3 Siswa & 13 Siswa \\
$56-75$ & Cukup Mampu & 17 Siswa & 26 Siswa & 16 Siswa & 11 Siswa \\
$10-55$ & Kurang Mampu & 12 Siswa & - & 13 Siswa & - \\
\hline
\end{tabular}

Berdasarkan hasil penelitian yang diperoleh, dapat disimpulkan bahwa terdapat pengaruh metode sosiodrama pada kelas eksperimen hal tersebut dapat dilihat dari rata-rata tes awal sebesar 60,63 dan tes akhir 81,88 dengan korelasi 0,75 dan besar pengaruh $56 \%$. Perbedaan kemampuan menentukan unsur intrinsik cerpen

\section{Pembahasan}

Besar Pengaruh metode sosiodrama terhadap kemampuan menentukan unsur intrinsik cerpen pada kelas eksperimen dihitung menggunakan koefisien determinasi, dan ditemukan besar koefisien determinasi adalah 0,56 artinya metode sosiodrama berpengaruh $56 \%$ terhadap kemampuan menentukan unsur intrinsik cerpen pada kelas eksperimen (kategori sedang).

Berdasarkan hasil uji-t kelas eksperimen dan kelas kontrol pada tes awal memiliki $t_{\text {hitung }}=$ 1669 dan $t_{\text {tabel }}=1,999$, sehingga tes awal siswa antara kelas eksperimen dan kelas kontrol dapat dilihat dari hasil uji t diperoleh $t_{\text {hitung }}=21,708$ dan $t_{\text {tabel }}=1,999$ memenuhi kriteria $t_{\text {hitung }}>$ $t_{\text {tabel }}$ sehingga terdapat perbedaan pada posttest kelas eksperimen dan kelas kontrol.

kelas eksperimen dan kelas kontrol memenuhi kriteria $t_{\text {hitung }}<t_{\text {tabel }}$. Hal ini menunjukkan bahwa tidak terdapat perbedaan pada kemampuan menentukan unsur intrinsik cerpen sebelum diberikan perlakuan. Hal ini sesuai dengan salah satu karakteristik penelitian eksperimen yang dikemukakan oleh Ruseffendi (dalam Noviana, 2008) bahwa equivalensi subjek dalam kelompokkelompok yang berbeda perlu ada, agar apabila ada hasil berbeda yang dipeoleh kelompok, itu 
disebabkan karena tidak equivalennya kelompokkelompok itu, tetapi karena adanya perlakuan.

Setelah mengalami proses pembelajaran sebanyak tiga kali pertemuan dikelas eksperimen dan kelas kontrol, selanjutnya siswa dari kelas eksperimen dan kelas kontrol diberikan tes akhir (postest). Pemberian tes akhir (postest) bertujuan untuk mengetahui pengaruh metode sosiodrama pada kelas eksperimen dan perbedaan kemampuan antara kelas eksperimen dan kelas kontrol dalam pembelajaran menentukan unsur intrinsik cerpen setelah diberikannya perlakuan.

Baerdasarkan hasil uji-t kelas eksperimen dan kelas kontrol pada tes akhir memiliki $t_{\text {hitung }}=21,708$ dan $t_{\text {tabel }}=1,999$, sehingga tes akhir kelas eksperimen dan kelas kontrol memilki kriteria $\quad t_{\text {hitung }}>t_{\text {tabel }}$ yang berarti terdapat perbedaan kemampuan menentukan unsur intrinsik cerpen antara siswa yang belajar menggunakan metode sosiodrama dan siswa yang belajar dengan metode ceramah/ hanya membacakan saja. Perbedaan terhadap kemampuan menentukan unsur intrinsik cerpen pada tes akhir disebabkan oleh perlakuan yang berbeda, pada kelas eksperimen diberikan

\section{SIMPULAN DAN REKOMENDASI}

Berdasarkan hasil analisis data dan temuan yang diperoleh dalam penelitian ini dapat disimpulkan bahwa perlakuan metode sosiodrama pada kelas eksperimen berpengaruh terhadap kemampuan menentukan unsur intrinsik cerpen siswa dibandingkan dengan perlakuan metode ceramah/konvensional pada kelas kontrol. Hal tersebut dapat dilihat dari rata-rata kemampuan menentukan unsur intrinsik cerpen di kelas eksperimen yang lebih tinggi yaitu pada saat tes awal dengan rata-rata 60,63 dengan standar deviasi 9,82 menjadi 81,88 dengan standar deviasi 8,30 pada saat tes akhir. Berdasarkan rata-rata nilai tes awal dan tes akhir tersebut terlihat adanya perbedaan kemampuan menentukan unsur intrinsik cerpen sebelum dan sesudah mendapatkan perlakuan dengan metode sosiodrama. Sesuai dengan hasil uji t pada tes akhir yang memenuhi kriteria $t_{\text {hitung }}>t_{\text {tabel }}$ yaitu 21,708>1,999 yang menunjukkkan $H_{a}$ perlakuan pembelajaran menggunakan metode sosiodrama, sedangkan pada kelas kontrol diberikan perlakuan metode ceramah.

Tes awal (pretest) kelas kontrol terdapat 3 (9\%) siswa berkategori mampu, 17 (53\%) siswa berkategori cukup mampu, dan 12 (38\%) siswa berkategori kurang mampu. Sedangkan pada saat tes awal (pretest) kelas eksperimen terdapat 3 (9\%) siswa berkategori mampu, 16 (50\%) siswa berkategori cukup mampu, dan $13(41 \%)$ siswa berkategori kurang mampu.

Tes akhir (posttest) kelas kontrol terdapat $6(19 \%)$ siswa berkategori mampu, 26 (81\%) siswa berkategori cukup mampu. Sedangkan pada tes akhir (posttest) kelas eksperimen terdapat 11 (34\%) siswa berktegori cukup mampu, 13 (41\%) siswa berkategori mampu, dan $8(25 \%)$ siswa berkategori sangat mampu.

Berdasarkan pembahasan hasil penelitian dapat disimpulkan bahwa hipotesis yang diajukan dapat diterima. Dengan demikian terdapat pengaruh dan perbedaan kemampuan menentukan unsur intrinsik cerpen dengan menggunakan metode sosiodrama pada siswa kelas V SD Negeri 131 Pekanbaru

diterima dan $H_{o}$ ditolak, artinya terdapat perbedaan kemampuan menentukan unsur intrinsik cerpen antara kelas eksperimen dan kelas kontrol. Hal ini menunjukkan metode sosiodrama berpengaruh terhadap kemampuan menentukan unsur intrinsik cerpen siswa kelas V SD Negeri 131 Pekanbaru (kelas eksperimen). Dengan korelasi 0,56 dan besar pengaruh metode sosiodrama pada kelas eksperimen sebesar $56 \%$

Berdasarkan pada pemaparan simpulan di atas, maka peneliti memberikan rekomendasi sebagai berikut:

1. Untuk meningkatkan kemampuan menentukan unsur intrinsik cerpen, diharapkan guru kelas untuk lebih mengadakan kreasi baru dalam mengajar.

2. Kepada peneliti selanjutnya dapat meneliti lebih dalam lagi mengenai pengaruh serta perbedaan kemampuan yang terjadi pada kelas eksperimen 
dan kelas kontrol dengan menggunakan metode sosiodrama.

\section{DAFTAR PUSTAKA}

Arikunto, S. (2013). Prosedur Penelitian. Jakarta: Rineka Cipta.

Bengoche,et all. (2018). An emergent bilingual child's multimodal choices. Journal of Early Childhood, 18(1), 38-70.

Djamarah, S.B., Dkk. (2010). Strategi Belajar Mengajar. Jakarta: Rineka Cipta.

Hasan, M. (2009). Pendidikan anak usia dini. Jogjakarta: Diva Press.

Kurniaman, O \& Hamizi. (2009). Teori dan Sejarah Sastra Indonesia. Pekanbaru: Cendikia.

Noviana, E. (2008). "Penggunaan Tegnologi Multimedia Interaktif dalam Pembelajaran Ilmu Pengetahuan Sosial untuk Meningkatkan Pemahaman dan Retensi Siswa (Studi Eksperimen Kuasi di Sekolah Dasar Negeri Kota Pekanbaru)". Tesis tidak dipublikasikan. Bandung. Universitas Pendidikan Indonesia.

Octaviana, P.S. (2017). Pengaruh Metode Sosiodrama terhadap Hasil Belajar dan Sikap Tanggung jawab dalam Pembelajaran PKN. Jurnal Bahastra, 14 (1), 35.

Sugiono. (2016). Metode Penelitian Pendidikan. Bandung: Alfabeta.
Tristiantari. (2017). An Effect Of Sociodrama Method Implementation In Students Language Skill At Fourth Grade Elementary School In Cluster XII Of Buleleng District. Journal Of Education Technology, 1 (1), 4550.

Ulon, S. (2018). Collective shadows on the sociodrama stage. International Journal of Jungian Studies. Routledge (Online). www.scholar.google.com. (diakses 6 September 2018).

Wati, U.E. (2016). Penggunaan Metode Sosiodrama dalam Peningkatan Pembelajaran Bahasa Indonesia bagi Siswa Kelas V SD. Jurnal Kalam Cendikia, 4 (2), 171-177.

Yulisna, R. (2017). Kontribusi Kemampuan Memahami Cerpen Terhadap Keterampilan Menulis Cerpen Siswa Kelas XI SMA Negeri 4 Padang. Jurnal Gramatika, 2 (2), 72-83. 